\title{
Application of Driven Teaching in Physical Education Curriculum
}

\author{
Zou Yebing \\ Jiangxi University of Traditional Chinese Medicine, Physical Education Department, Nanchang \\ Jiangxi, China, 330004
}

Keywords: driven; teaching; physical education; curriculum;

Abstract: Driven teaching is one of the advanced teaching methods in modern teaching process. The introduction of driven teaching method in physical education curriculum can improve the teaching quality, therefore, the research on application of driven teaching in physical education curriculum is proposed. First, the application process of driven teaching in physical education curriculum was researched detailedly; next, the application effect of driven teaching in physical education curriculum was obtained through investigation; finnally, the application features, advantages of driven teaching in physical education curriculum were analyzed through the application effect, and corresponding propositions were given to provide optimization of physical education curriculum with theoratical basis.

\section{Introduction}

Physical education curriculum can't get real attention in the traditional Chinese teaching mode. To promote students' physical quality training to meet actual needs, it is necessary to reform the existing physical education teaching mode. As a new teaching mode, driven teaching requires teachers to guide students to learn the course content by arranging tasks before teaching ${ }^{[1]}$. In the process of exploring the problem, the students realize the understanding of the teaching objectives and learning difficulties in the classroom. The sports learning process is a process of constructing a positive system. In the process of learning knowledge, students learn mainly by constructing the meaning of existing knowledge. Students mainly acquire social and life knowledge through activities and practice, so this is also the basis of driven teaching ${ }^{[2]}$. Introducing a driving teaching method in physical education is also a new attempt to benefit the curriculum. In the process of exploring tasks and problems, students gradually master the knowledge content, skills, knowledge points, etc., and help the driven teaching to play a positive role in the application of physical education curriculum.

\section{Investigation of application of driven teaching in physical education curriculum}

In the process of driven teaching, teachers need to formulate different learning content tasks according to learning objectives, and adopt group learning styles through different standards to evaluate the collective achievements in group cooperation. In order to explore the application effect 
of driven teaching in physical education curriculum, students of different grades in a certain school are investigated. Further conclusions were obtained by analyzing the survey results ${ }^{[3]}$.

\subsection{Research methods and purposes}

In the course of the investigation, the literature research method, the expert interview method, and the questionnaire survey method were mainly used for investigation and research. Through the analysis of the results of different modes of student physical education teaching, the application effect of driven teaching in physical education curriculum is studied.

\subsection{Survey object and method}

In this survey, students of different grades of a certain school were selected as experimental subjects. 21 males and 21 females were selected as the experimental subjects. The experimental subjects were divided into two groups on average, the driven physical education teaching mode was the experimental group, and the traditional physical education teaching mode was the control group. According to the requirements, the experimental group strictly follows the driven physical education teaching mode, and the basic flow chart of the driven physical education teaching mode is shown in Figure 1:

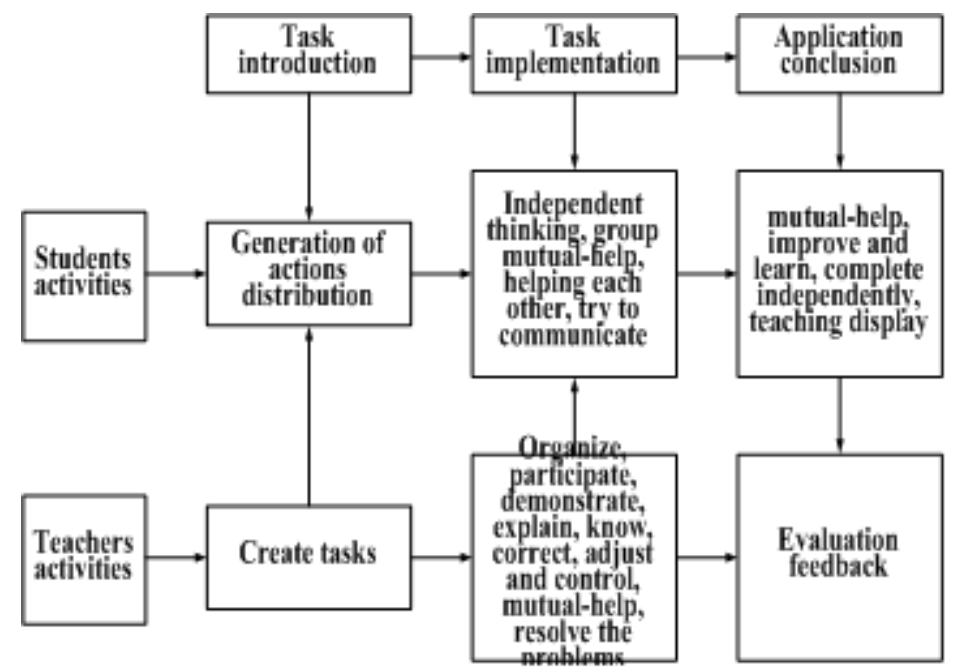

Figure1. Basic flow chart of the driven physical education teaching mode

\subsection{Survey data analysis}

In the course of the investigation, it is necessary to test the physical fitness, skill level and skill knowledge of the two groups of students. The results are shown in Table 1:

Table 1 Comparison of student quality

\begin{tabular}{lllll}
\hline Items & Control group & Experimental group & $P$ & $T$ \\
\hline Age & $2.1 .33 \pm 0.21$ & $21.14 \pm 0.15$ & $>0.05$ & 0.72 \\
Weight & $72.14 \pm 1.49$ & $67.52 \pm 1.41$ & $>0.05$ & 2.24 \\
Stature & $175.07 \pm 1.06$ & $173.02 \pm 1.07$ & $>0.05$ & 1.35 \\
Good-monring & $15.09 \pm 1.09$ & $16.42 \pm 0.97$ & $>0.05$ & 0.91 \\
& & & & \\
Push-up & $13.71 \pm 0.84$ & $11.7 \pm 0.69$ & $>0.05$ & 1.83 \\
V-up & $14.00 \pm 0.86$ & $14.85 \pm 0.49$ & $>0.05$ & 0.89 \\
Pull-up & $11.09 \pm 0.52$ & $9.47 \pm 2.94$ & $>0.05$ & 1.94 \\
\hline
\end{tabular}


According to the above table, the physical fitness and skill knowledge of the two groups of students are similar. In the course of the experiment, the experimental variables should be mainly controlled while avoiding the efficiency of the experimenter.

\subsection{Analysis of survey results}

After the same class teaching was conducted for the two groups of students, the results of the students were compared in order to verify the results. The results are shown in Table 2.

Table 2 Comparison of technical scores between the two groups of students after the experiment

\begin{tabular}{|c|c|c|c|c|}
\hline Items & Control group & Experimental group & $P$ & $T$ \\
\hline Support rotation & $7.89 \pm 0.19$ & $8.34 \pm 0.15$ & $<0.05$ & 1.82 \\
\hline $\begin{array}{l}\text { Hanger flexion } \\
\text { and extension }\end{array}$ & $8.49 \pm 0.12$ & $8.88 \pm 0.89$ & $<0.05$ & 2.49 \\
\hline $\begin{array}{l}\text { Backstay } \\
\text { backswing }\end{array}$ & $8.20 \pm 0.72$ & $8.69 \pm 0.10$ & $<0.05$ & 2.60 \\
\hline $\begin{array}{ll}\text { Riding } & \text { support } \\
\text { winding } & \end{array}$ & $7.39 \pm 0.18$ & $8.01 \pm 0.18$ & $<0.05$ & 2.39 \\
\hline Forward roll & $8.58 \pm 0.16$ & $9.10 \pm 0.72$ & $<0.05$ & 3.01 \\
\hline Headstand & $7.77 \pm 0.18$ & $8.43 \pm 0.14$ & $<0.05$ & 1.80 \\
\hline
\end{tabular}

Analysis of the above table shows that after the experiment, the students in the experimental group were significantly higher than the control group, and the technical level was significantly improved. It also proves that the application of driven teaching in physical education curriculum has obvious effects.

\section{Application effect of driving teaching in PE course}

\subsection{The application characteristics of driving teaching in physical education course}

Through the analysis of the above survey results, it can be seen that the application of driven teaching in physical education curriculum enables students to better master the theoretical knowledge and action technology in the curriculum ${ }^{[4]}$. While helping students improve their learning efficiency, they will develop students' interest in sports and increase their learning experience. In the process of physical education, students improve their interpersonal skills and improve the efficiency of physical education classrooms through mutual cooperation. Driven teaching in the application of physical education curriculum, the organizational form of group teaching is used to stimulate students' enthusiasm for learning. It is necessary to abandon the traditional teacher-led teaching form, increase the communication between teachers and students, and enable students to learn knowledge independently through discussion and cooperation ${ }^{[5]}$. This kind of learning can minimize the gaps in students' learning process, and is more beneficial to middle and low level students, and it can better help them improve their skills and learning time. The driving physical education teaching mode is different from the traditional teaching mode. The teacher has changed from the main body status to the dominant position in the teaching, and has become the helper, guide and participant in the teaching process. In the teaching process, teachers combine a variety of modern multimedia teaching methods such as pictures, videos and audio to stimulate students' interest in learning. The driven physical education teaching mode still uses the class collective as the teaching premise, and carries out different task design for the learning level 
of different students in the same class to help students better achieve the teaching goal ${ }^{[6]}$. In this process, because different students have different learning tasks, it is more conducive to observing students' ability to observe, analyze and solve problems in the learning process, and to better fulfill the development rules and quality teaching requirements of physical education.

\subsection{The application advantage of driven teaching in physical education curriculum}

The main advantages of the application of driven teaching in physical education curriculum are to stimulate students' initiative, help to cultivate students' comprehensive quality and improve learning efficiency ${ }^{[7]}$. In terms of stimulating students' initiative, students are mostly in adolescence and have more youthful vitality. In the process of teaching, teachers need to abandon the original monotonous course means. Through driven teaching, students can feel more exploration and challenges in learning, which can attract more students to participate actively in learning, so that students can have more sense of responsibility and mission in learning. Teachers can correctly guide students' problems in the process of inquiry, so that students' subjective consciousness and initiative can be better played. In the aspect of students' comprehensive quality training, driven teaching can help students to fully exert their imagination and creativity in the process of learning, and help students to develop their comprehensive quality. When students complete their learning tasks, because of their sense of responsibility and mission, students can fully mobilize all parts of the body to work hard to complete the task. In the process of completing the task, the students' cooperation ability and inquiry ability are improved, and at the same time, the students' persevering character can be cultivated. Driven teaching is different from traditional physical education teaching mode. Students have a sense of purpose in learning, and the improvement of students' subjective consciousness can maximize the initiative of students. In the classroom, students will try their own brain analysis and consciously explore the best solutions to the problem objectives, so that the classroom efficiency is improved.

\subsection{Related optimization suggestions}

The application of driven teaching in physical education curriculum is mainly guaranteed by teaching time. In the teaching process, teachers need to clarify the specific teaching tasks and objectives of each lesson ${ }^{[8]}$. Driven teaching is the core content of the entire physical education model. Teachers and students should aim at accomplishing different stages of the task. Teachers must ensure their dominant position in teaching, which is also an important guarantee for students to complete their tasks. Teachers should correct the deviations and problems and disputes in the analysis of problems in the process of self-study, and help students to understand the knowledge they have learned. At the same time, because the driven physical education teaching puts forward higher requirements for teachers, teachers need to have higher knowledge reserves, professional skills and teaching ability. And it also requires teachers to solve different problems raised by students according to different teaching environments. Although driven teaching has a significant role in physical education, the limitations in the application process cannot be ignored. In the development of teaching methods, driven physical education should not only consider the main body and content of teaching, etc., but also cooperate with other different teaching methods. According to different teaching requirements, the combination of driven teaching method and various teaching methods can achieve better teaching results. 


\section{Conclusion}

The application of driven teaching in physical education curriculum can better meet the requirements of new curriculum standards and improve students' learning efficiency. In the research process, through the study of its application process, the effectiveness of the application of driven teaching in physical education curriculum is verified. What's more, the application effect is studied, mainly through the application characteristics and advantages, and the suggestions are given. It helps physical education courses better meet the learning needs of students.

\section{References}

[1] Wang Junfeng. Let the Students Get Physical Education from the Physical and Mental Reconstruction--The Construction of the Teaching Model of Happy Physical Education in the Public Physical Education Curriculum in Colleges and Universities[J]. Journal of Wuhan Institute of Physical Education, 2017, 51(8): 74-77.

[2] Zhou Meifang, Huang Zhuo, Cheng Qilian. Research on the Internationalization of Large-scale Sports Events Driven by Cities —- Taking Tianjin as an Example[J]. Jiangxi Social Sciences, 2017(2):246-251.

[3] Wan Xiaohong, Wang Haiming. Driving and Constructing the National Sports Culture Identity of Silk Road by Digital Technology [J]. Journal of Wuhan Institute of Physical Education, 2017, 51(11): 14-18.

[4] Wang Cong. Simulation of 3D Vision Motion Range Tracking Method in Sports [J].Computer Simulation, 2017, $34(01): 245-248$.

[5] Liu Huanan, Ji Liu. Reflections on the Reform of Football Specialized Courses for Physical Education Majors in China_-Based on the Training Orientation of Compound Soccer Teachers[J]. Journal of Beijing Sport University, 2017, 40(3): 79-85.

[6] He Tao. Analysis of the Development of Mass Sports Culture and School Physical Education-C Comment on the Theory and Practice of Physical Fitness Training in Mass Sports[J]. Journal of the Chinese Society of Education, 2017, 40(1): 14-18.

[7] Liu Jin. New Exploration of Physical Education Teaching Mode in Colleges and Universities-CComment on "Return of Value of Physical Education_-Research on Physical Education Teaching Mode of Promoting College Students' Quality Education and Lifelong Physical Education”[J]. Journal of the Chinese Society of Education, 2017, 51(12): 14-18.

[8] Xu Shouliang. Research on the Reform and Development of Physical Education in Higher Vocational Colleges-— A Review of Research on the Current Situation and Development of Physical Education in Higher Vocational Colleges[J]. Educational Review, 2017(7): 166-166. 